\title{
ANALYSIS OF LAND IN PROTECTED AREAS OF GAS PIPELINES OF DIFFERENT PRESSURE ON THE EXAMPLE OF THE FERGHANA REGION
}

\author{
Abdullayev Ibrohim Numanovich ${ }^{1}$ \\ $\mathrm{PhD}$ of Fergana polytechnic institute, \\ Uzbekistan $^{1}$
}

\author{
Marupov Azizxon Abbosxonovich ${ }^{2}$ \\ $\mathrm{PhD}$ applicant of Fergana polytechnic institute, \\ Uzbekistan $^{2}$
}

\author{
Tulqin Ahmedov ${ }^{3}$ \\ Senior teacher of Fergana polytechnic institute, \\ Uzbekistan $^{3}$
}

Article DOI: https://doi.org/10.36713/epra2378

\begin{abstract}
ANNOTATION
Protection zones of underground and aboveground gas pipelines with different pressure indicators are of great importance not only for safety, also and for present and future land use. The use of these lands for domestic and agricultural needs, with the correct organization of cadastral relations, is relevant to this issue. At the same time, an example is provided of a gas transport pipeline section with a pressure indicator of $6 \mathrm{~kg} / \mathrm{sm}^{2}$.
\end{abstract}

KEY WORDS: security zones, land plot, information about zones, zones with high pressure, gas lines, gas pipelines, bonus points, engineering networks, various buildings, construction of buildings and structures.

\section{INTRODUCTION}

Laying underground and above-ground communications of different lengths, which require significant land area not only for pipelines themselves, but also for their protected areas, is a responsible task, as gas is:

First, an explosive substance;

- In the second gas pipeline routes require occupation for significant times of land with different points of ball bonitettes. [1]

Initially, the categories of the gas pipelines themselves should be defined:

- Low pressure pipelines, where the pressure value in pipes reaches $0.05 \mathrm{kgf} / \mathrm{cm}^{2}$;

- Medium pressure pipelines, where pressure index is from 0.05 to $3.0 \mathrm{kgf} / \mathrm{cm}^{2}$;

- High pressure pipelines, where the pressure value varies from 3.0 to $6.0 \mathrm{kgf} / \mathrm{cm}^{2}$.

There are situations in which the pressure in the gas pipeline structure may exceed the established limits. In some cases it reaches $12.0 \mathrm{kgf} / \mathrm{cm}^{2}$ (highest pressure line). The arrangement of the system with such pressure indicators requires separate calculations. All gas pipelines are classified not only by pressure, but also depending on the material from which they are produced.

Pipelines of the first category are used for supply of gas to small-scale economic systems, the second and third categories are installed for different production enterprises.

In the Fergana region, pipelines of these three categories, laid underground (closed) and above-ground (open) installation options, occupy significant land.

\section{OBJECTIVES}

In practice, the underground method of laying gas pipelines is predominantly used. Their depth of laying depends on the indicator of gas humidity and depth of soil freezing. In our climatic conditions they are mounted from $80 \mathrm{~cm}$ below the level of soil freezing $(60 \mathrm{~cm})$ - i.e. $140 \mathrm{~cm}$ and deeper. All necessary restrictions, including distances from the guard lane lines to the buildings, are 
described in the relevant regulatory documentation. (APPENDIX N-4 to the Resolution of CM RUz dated 10.12.2008y. No. 271 "In order to ensure the monitoring of compliance with safety measures, assessment of adequacy and effectiveness of measures to prevent and eliminate the consequences of accidents at a dangerous production facility, the Law of the Republic of Uzbekistan "On Industrial Safety of Hazardous Production Facilities" establishes the procedure for the development and submission of a declaration of industrial safety of a hazardous production facility to State bodies, public associations and citizens ".[2]

A gas pipeline communication guard zone is a space that is located between a pipe and two conditional lines located parallel to the sides of it. The distance from the pipeline axis to these lines may vary, as it depends on the pressure within the communication.

\section{METHODOLOGY}

Consider examples of guard areas for different gas pipelines:

- For communications that are laid in an open way, the protection area will be $2 \mathrm{~m}$ on each side of the pipe;

- For points performing gas adjustment in the pipeline, the conditional closed line of the protection zone is $10 \mathrm{~m}$ from their borders. For private gas adjustment points, the security area is not regulated;

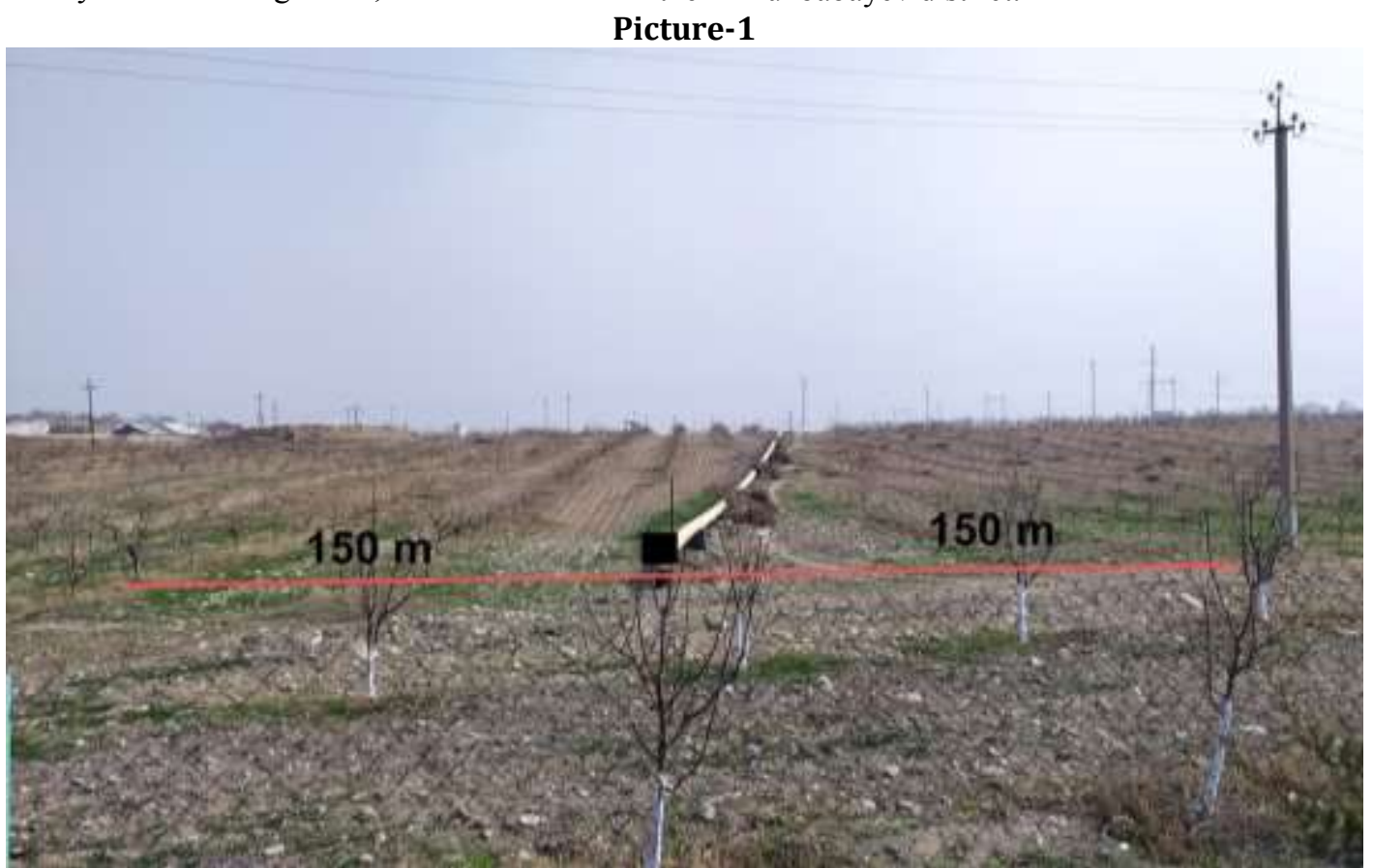

Picture 1 shows a snapshot of the good state of the high pressure gas pipeline route with a diameter of $216 \mathrm{~mm}$, with a value of $3.2 \mathrm{kGs} / \mathrm{cm}^{2}$, on
- The protection area for gas pipelines laid underwater is $100 \mathrm{~m}$;

- $\quad$ For communications laid in forest fields and in territories with wood-shrub vegetation, the protection zone is $3 \mathrm{~m}$ (in case of underground laying of the route). And for communications mounted above the ground, the distance from the tree to the pipe must be no less than the height of that tree;

- Pipes with a cross-sectional index of at least $80 \mathrm{~mm}$ are generally used for private purposes. For such a pipeline, the guard area will be $2 \mathrm{~m}$ on each side.

The open method of laying is used when there is no possibility of underground installation due to the presence of natural or artificial obstacles such as water bodies, ravines, various buildings and various other communications.

In case of gas pipeline laying variants, their protection zones are defined, which are a space located between the pipe and two conditional lines located in parallel on the sides of it along the whole route. The distance from the pipeline axis to these lines depends on the pressure within the pipe.

\section{STATISTICAL DESIGN}

As an example, Pictures 1 and 2 show a pipeline with a high pressure index laid by an open above-ground method in the southern part of the large ring road of the city of Fergana, in the area of the Akhunbabayev district.

Picture-1

the section where the underground gasket line, due to the perpendicular intersection with the underground high-voltage cable power line $10.6 \mathrm{~kW}$ and the water 
pipeline (D-1000 mm), changes to the above-ground section. The picture shows how much the represented area is saturated with underground communications and above-ground engineering communications and how land is usefully used. Here, a field with conservation areas is planted with dwarf fruit trees lacking a massive root system. In addition to plantations, the land is used for planting gardenmelon crops. Land use at the site has acquired cultural cadastral relations, which allow to specify revenues both at the expense of land owners and land users, as well as in the budget.

However, the acquiescence of the engineering communications services or municipal authorities, or the illiteracy of the population, often leads to various conflict situations between the economy and the cadres. For example, Picture 2 shows an example where a gas pipeline is laid on an already built-up area, without the presence of a security zone. In this case, there are two options for solving the problem:

- Or individual house buildings shall be demolished within the defined semicircle;

- Or the pipeline route itself shall be re-rated to a safe distance from the structures. An option with lower material and moral costs is acceptable here, depending on the prospect of operating the gas pipeline.

The current situation is urgent, as it is known that any violation of technical norms and deviations from the rules can lead to trouble, problems, accidents and up to a man-made disaster.

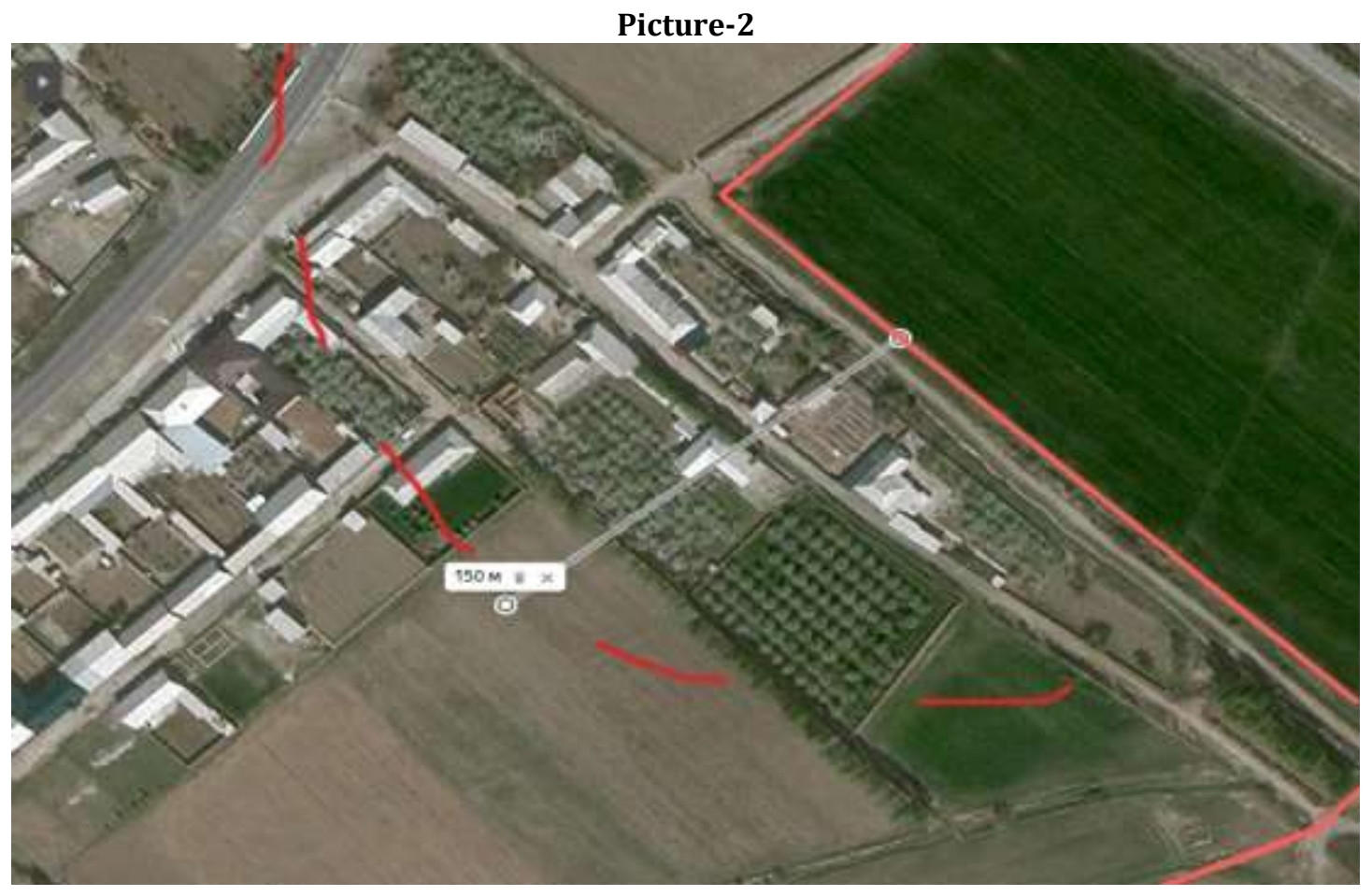

As known that certain restrictions are imposed on the territory that lies within the protection zone, such as:

- The construction of various buildings is categorically prohibited;

- If part of the bridge enters the limits of the protection zone of the gas transportation communication, then it is prohibited to demolish it or work on its reconstruction without obtaining permission from the relevant authorities;

- The development of landfills in the security zone is prohibited;

- It is prohibited to store toxic wastes, acids, cheeks or other aggressive chemical compounds within the protection zone;
- It is prohibited to erect blocking elements within the protection area (e.g. fences);

- In the territory that lies within such a zone, in no case should fire be fired;

- It is forbidden to treat the soil at a depth which exceeds the value of $30 \mathrm{~cm}$.

\section{RESULTS}

For gas pipeline structures that are in the process of laying, approval of such zones is carried out in the presence of the owner of the site. For existing gas transportation lines, the presence of the owner of the land plot is not mandatory.

Laying a gas pipeline communication on a section of a private house is a responsible task, as gas 
is an explosive substance. The installation of the gas pipeline shall comply with all building codes and regulations and take into account certain restrictions imposed on these systems for safety purposes. First of all, in order to understand the issue, it is necessary to understand the varieties of gas pipelines.

Optional variants for laying gas pipeline systems. To date, there are three main options for the installation of gas pipeline structures:

- underground (closed);

- elevated (open);

- internal.

The closed method of laying gas pipeline communications is the most common to date. The depth of the pipe laying depends on the gas humidity index. If wet gas moves through the pipe, then it is laid below the level of soil freezing. And pipe with dry gas is mounted from $80 \mathrm{~cm}$ below ground level. All necessary restrictions, including distance to residential construction, are described in the relevant regulatory documentation. Steel or polyethylene pipes can be installed in a closed manner.

- The open method is generally used if it is not possible to mount the system underground due to natural or artificial obstacles. Such barriers include:

- reservoirs;

- ravines;

- various constructions;

- other communications.

\section{SUGGESTIONS}

Only pipes with high strength are allowed for open laying. Such description includes steel products, which are the main structural elements of such systems. The distance of the open steel gas pipeline to the residential building is not set.

The internal method of laying gas pipeline systems implies their location inside the premises. In such a case, the distance to walls and other indoor objects is determined as appropriate.

Depending on the type of zones within its territory, certain restrictions on the use of land plots are established. These restrictions are mainly related to the possibility of placing capital construction facilities in principle, or compliance with certain parameters of the object under construction, carrying out certain construction works.[3]

\section{CONCLUSION}

In conclusion, it should be noted that such zones, as indicated by the example in the region and in the valley, as well as in the Republic, are not small. Therefore, practical analytical study and theoretical comprehensive survey provides an opportunity to develop recommendations on regularization of the state of protected areas, design and alienation of new protected areas. This is important in the rapid development gas industrial complex of the country, in the laying of new communication networks, in the construction of new gas pipeline lines requiring large areas for construction, as well as in the protection of the rights of legal and private entities. Our careful and insensitive attitude towards land should increase the efficiency of land use with environmental cleanliness and transfer it to new generations.

\section{REFERENCES}

1. Yunusaliyev E.M., Xakimova K.R., Marupov A.A., Fbdulhalilov B.K., "Geographical Features of the Structure and the Content of the Fergana Valley Ecological Atlas". ijarset.com "INTERNATIONAL JOURNAL OF ADVANCED RESEARCH IN SCIENCE, ENGINEERING AND TECHNOLOGY”. October 2019. 6-11, p: 11510-11515, ORCID: 00000002-5120-4359

2. https://nrm.uz/contentf?doc $=390537$ polojenie_o_po ryadke_razrabotki_i_predstavleniya_deklaracii_pro myshlennoy_bezopasnosti_gosudarstvennym_organa $m \_o b s h c h e s t v e n n y m \_o b e d i n e n i y a m \_i \_g r a j d a n a m \_(p$ rilojenie_n_4_k_postanovleniyu_km_ruz_ot_10_12_ 2008_g_n_271)

3. Abdullayev I.N., Marupov A.A., THE ANALYSIS OF LANDS IN SECURITY ZONES OF HIGH-VOLTAGE POWER LINES (POWER LINE) ON THE EXAMPLE OF THE FERGANA REGION, 6/2/2020, p-55-58, ORCID: 0000-0002-5120-4359, https://doi.org/10.36713/epra3977 